\title{
Evaluation of Sensitivity and Specificity of Interleukins 25 and 33 in Diagnosis of Pediatric Asthma
}

\author{
Abeer Thaher Naji AL-Hasnawi \\ Medical Microbiology Department, College of Medicine, University of Kerbala, Iraq.
}

\begin{abstract}
The roles of interleukin 25 (a member of the interleukin 17 family) and interleukin $\mathbf{3 3}$ (a member of the interleukin 1 family) in asthma and airway hyper responsiveness are yet to be fully understood. The aim of this study was to investigate the roles of IL- 25 and IL- 33 in the diagnosis of pediatric asthma and their association with severity and treatment of the disease. This was a case-control study comprising $\mathbf{7 4}$ children with asthma as the patient group and $\mathbf{7 5}$ healthy children as the control group. The age of the participants ranged from 1 to 15 years. Levels of IL- 25 and IL- 33 in the serum were measured using ELISA kits. The highest positive predictive values (88.9\%) occurred in IL- 25 with sensitivity and specificity of about $\mathbf{9 7 . 3 \%}$ and $\mathbf{8 8 . 0 \%}$ respectively, while the sensitivity and specificity of IL- 33 were about $51.4 \%$ and $66.0 \%$ respectively, with a positive predictive value of about (60.3\%). The present study thus found that IL- 25 had higher diagnostic sensitivity and specificity values than IL- 33 in children with asthma. In addition, both interleukins were found to have a statistical significance regarding treatment of the disease in children.

Keywords: Pediatric asthma, IL-25 and IL-33, Sensitivity and Specificity
\end{abstract}

*Correspondence: abeer_thaher@yahoo.com

(Received: March 12, 2021; accepted: May 27, 2021)

Citation: AL-Hasnawi ATN. Evaluation of Sensitivity and Specificity of Interleukins 25 and 33 in Diagnosis of Pediatric Asthma. J Pure Appl Microbiol. 2021;15(2):845-850. doi: 10.22207/JPAM.15.2.39

(C) The Author(s) 2021. Open Access. This article is distributed under the terms of the Creative Commons Attribution 4.0 International License which permits unrestricted use, sharing, distribution, and reproduction in any medium, provided you give appropriate credit to the original author(s) and the source, provide a link to the Creative Commons license, and indicate if changes were made. 


\section{INTRODUCTION}

Asthma is a disease characterized by chronic inflammation of the airways. This inflammation is distinguished by recurrent events of breathlessness, wheezing, chest tightness and coughing in the early morning or during the night in susceptible individuals. Several types of cells and cellular elements are associated with this disease and play an important role in its pathogenesis; these include T lymphocytes, neutrophils, epithelial cells, eosinophils and mast cells ${ }^{1}$. The risk factors of asthma are associated with the interactions between environmental and genetic factors. Approximately hundreds of genetic variants are correlated with an elevated risk of asthma disease ${ }^{2}$.

Several viral infections are also considered as risk factors for developing asthma ${ }^{3}$. A study demonstrated that viral infections are associated with the chronic inflammation of airways and exacerbation of asthma in children and adults ${ }^{23}$. Stable and acute exacerbations of asthma are also associated with bacterial infections, while the contribution of fungal infection to asthma is not clear. In addition, the exposure to airborne environmental factors like pollutants and tobacco smoke increases the risk of asthma ${ }^{3}$.

Exposure to environmental and genetic factors, in addition to the alterations in the microbiome and metabolites, are associated with the emergence of lower airway inflammation ${ }^{4}$. The type 2 inflammation, observed in most patients with asthma, is associated with type $2 \mathrm{~T}$ helper cells. Specific cytokines such as interleukins 4 , 5 and 14, and some inflammatory cells and IgE immunoglobulin are also associated with Type 2 inflammation, which is usually found in allergic diseases and eosinophilic disorders 5 . Moreover, type 2 inflammation can be regulated by epithelial cells of the airway through some cytokines such as interleukins 25 and 33 and thymic stromal Iymphopoietin ${ }^{5}$. Both IL- 25 and IL- 33 are responsible for stimulating the group 2 innate lymphoid cells that participate in the initiation of type 2 immune response ${ }^{6}$.

IL- 25 directly stimulates eosinophils via upregulating the expression of ICAM-I, this leads to the production of several proinflammatory chemokines like macrophage inflammatory protein-1, monocyte chemoattractant protein-1, and interleukins 6 and 8 and ultimately delays apoptosis ${ }^{7}$. The expression of IL- 25 was found to increase in the bronchial asthma and also in the patients with eczema ${ }^{8}$. The expression of IL-25 and its receptor that induced by allergen correlated with the disease severity, in atopic asthma as well ${ }^{9}$. Furthermore, there is significant evidence connecting the effects of tobacco smoke exposure to reduced immune function, resulting in an imbalance in responses of both Th1 and Th 2 cells and, consequently, an increase in susceptibility to allergic diseases ${ }^{20}$. A study found that reduction in the number of Th1 adenoidal lymphocytes (IFN- $\gamma-\mathrm{CD} 8+$ ) in children was related to passive smoke exposure, leading to recurrent respiratory infections $^{21}$. The anti IgE omalizumab drug represents the major recommended treatment of severe asthma ${ }^{22}$.

\section{MATERIALS AND METHODS}

This case-control study was carried out at an outpatients clinic of asthma in the Kerbala Teaching Hospital for Children from September 2019 to December 2019. All the children included in this study were diagnosed according to medical history and clinical examination and also according to the criteria of the American Thoracic Society for asthma ${ }^{10}$.

Ethical approval for the study was acquired from the College of Medicine, University of Kerbala, Medical Research Bioethical Committee. Verbal approval was also taken from the parents of the children before obtaining samples. Written consent was waived by the parents because verbal consent was sufficient, according to the parents' opinion.

From a total of 149 participants in this study, 74 children ( 56 boys and 18 girls represented the patient group with an age rang of 1-15 years, and 75 healthy children represented the control group with the same sex and age distribution as the patient group but with no history of allergies, asthma or inflammatory diseases. Patients with inflammatory conditions other than asthma were excluded from this study. The stages of asthma severity were diagnosed as per the NAEPP/ EPR 3 guidelines ${ }^{11}$ by the specialist pediatricians.

From each participants about $5 \mathrm{cc}$ of venous blood was taken. Serum sample was separated and stored in deep freeze at $-20^{\circ} \mathrm{C}$ until 
analyzed. Levels of interleukins 25 and 33 were assessed with commercial ELISA kits (CUSABIO) with catalog numbers CSB-E11715h and CSBE13000h, respectively, by the using quantitative sandwich enzyme immunoassay technique.

\section{Statistical analyses}

Statistical Package for the Social Sciences (SPSS: version 20, IBM, Chicago, IL, USA) program was used for data entry and analysis. Non parametric tests, Mann-Whitney $U$ test and Kruskal-Wallis test, were used for the comparison of the mean and standard error of interleukins with the socio-demographic data in the patient group. Receiver-operating characteristic (ROC) curves were used to evaluate the diagnostic utility of interleukins as estimated by the area under the curve. Furthermore, the sensitivity and specificity in association with positive predictive value (PPV) and negative predictive value (NPV) were calculated for the patients relative to the healthy controls. $P<0.05$ was considered to be statistically significant.

\section{RESULTS}

The differences in the concentration of IL- 25 and IL- 33 according to sociodemographic and clinical variables in the patient group are demonstrated in Table 1. There are significant differences in the level of IL-25 according to type of treatment and higher concentration was found among patients receiving montelukaste $(P<0.029)$, Meanwhile the same significant

Table 1. Differences in the concentration of IL-25 and IL-33 according to different sociodemographic and clinical variables among asthmatic group.

\begin{tabular}{|c|c|c|c|c|c|c|}
\hline \multirow[t]{2}{*}{ Variable } & & \multirow[t]{2}{*}{$\mathrm{N}$} & \multicolumn{2}{|c|}{ Interlukin-25 } & \multicolumn{2}{|c|}{ Interleukin-33 } \\
\hline & & & Mean \pm SE & $P$ value & Mean \pm SE & $P$ value \\
\hline \multirow[t]{2}{*}{ Gender } & Male & 56 & $167.50 \pm 40.28$ & 0.112 & $1.30 \pm 0.06$ & 0.198 \\
\hline & Female & 18 & $295.27 \pm 69.60$ & & $1.08 \pm 0.11$ & \\
\hline \multirow[t]{2}{*}{ Eczema } & Positive & 8 & $25.32 \pm 15.33$ & 0.081 & $1.16 \pm 0.05$ & 0.383 \\
\hline & Negative & 66 & $172.96 \pm 38.43$ & & $1.26 \pm 0.06$ & \\
\hline Allergic & Positive & 40 & $163.23 \pm 41.92$ & 0.965 & $1.26 \pm 0.08$ & 0.879 \\
\hline rhinitis & Negative & 34 & $149.68 \pm 57.88$ & & $1.24 \pm 0.07$ & \\
\hline Allergic & Positive & 20 & $167.06 \pm 62.24$ & 0.933 & $1.39 \pm 0.08$ & 0.33 \\
\hline conjunctivitis & Negative & 54 & $149.94 \pm 41.89$ & & $1.20 \pm 0.06$ & \\
\hline Family history & Positive & 16 & $49.05 \pm 18.55$ & 0.247 & $1.31 \pm 0.12$ & 0.617 \\
\hline of eczema & Negative & 58 & $186.78 \pm 43.25$ & & $1.23 \pm 0.06$ & \\
\hline Family history & Positive & 50 & $138.68 \pm 40.38$ & 0.945 & $1.15 \pm 0.06$ & $0.013^{*}$ \\
\hline of asthma & Negative & 24 & $195.17 \pm 66.71$ & & $1.45 \pm 0.07$ & \\
\hline Family history & Positive & 58 & $188.38 \pm 43.30$ & 0.293 & $1.26 \pm 0.06$ & 0.599 \\
\hline of rhinitis & Negative & 16 & $43.26 \pm 13.02$ & & $1.20 \pm 0.10$ & \\
\hline \multirow{2}{*}{$\begin{array}{l}\text { Family history } \\
\text { of smoking }\end{array}$} & Positive & 34 & $107.61 \pm 35.58$ & 0.447 & $1.23 \pm 0.07$ & 0.845 \\
\hline & Negative & 40 & $198.98 \pm 56.22$ & & $1.27 \pm 0.08$ & \\
\hline \multirow{2}{*}{$\begin{array}{l}\text { Aggravating by } \\
\text { flu }\end{array}$} & Positive & 50 & $167.24 \pm 45.94$ & 0.229 & $1.29 \pm 0.06$ & 0.392 \\
\hline & Negative & 24 & $135.68 \pm 48.87$ & & $1.17 \pm 0.10$ & \\
\hline \multirow{2}{*}{$\begin{array}{l}\text { Aggravating by } \\
\text { dust }\end{array}$} & Positive & 40 & $200.38 \pm 60.65$ & 0.602 & $1.31 \pm 0.07$ & 0.501 \\
\hline & Negative & 34 & $105.96 \pm 23.17$ & & $1.18 \pm 0.08$ & \\
\hline \multirow[t]{4}{*}{ Treatment } & Montelukaste & 30 & $217.36 \pm 71.45$ & $0.029 *$ & $1.46 \pm 0.08$ & $0.002 * *$ \\
\hline & Corticosteroid\# & 4 & $1.77 \pm 0.14$ & & $1.50 \pm 0.09$ & \\
\hline & Mixed & 2 & $1.77 \pm 0.00$ & & $1.33 \pm 0.00$ & \\
\hline & No treatment & 38 & $133.86 \pm 35.67$ & & $1.05 \pm 0.06$ & \\
\hline \multirow[t]{2}{*}{ Severity } & Mild & 62 & $166.07 \pm 40.88$ & 0.196 & $1.27 \pm 0.06$ & 0.217 \\
\hline & Moderate & 12 & $110.12 \pm 34.06$ & & $1.41 \pm 0.13$ & \\
\hline
\end{tabular}

significant $\mathrm{p}$ - value, $* *$ highly significant $\mathrm{p}$ - value, \# inhaled corticosteroid $\mathrm{SE}=$ standered error of the mean, $\mathrm{P}=$ probability value 
Table 2. Sensitivity, specificity, positive, and negative predictive value for IL-25, and IL-33.

\begin{tabular}{lccccc}
\hline Variable & Cutoff value & Sensitivity & Specificity & PPV & NPV \\
\hline $\mathrm{IL}-25 \mathrm{pg} / \mathrm{ml}$ & $\geq 1.6350$ & $97.30 \%$ & $88.00 \%$ & $88.90 \%$ & $97.10 \%$ \\
$\mathrm{IL}-33 \mathrm{pg} / \mathrm{ml}$ & $\geq 1.3100$ & $51.40 \%$ & $66.00 \%$ & $60.30 \%$ & $58.10 \%$ \\
\hline
\end{tabular}
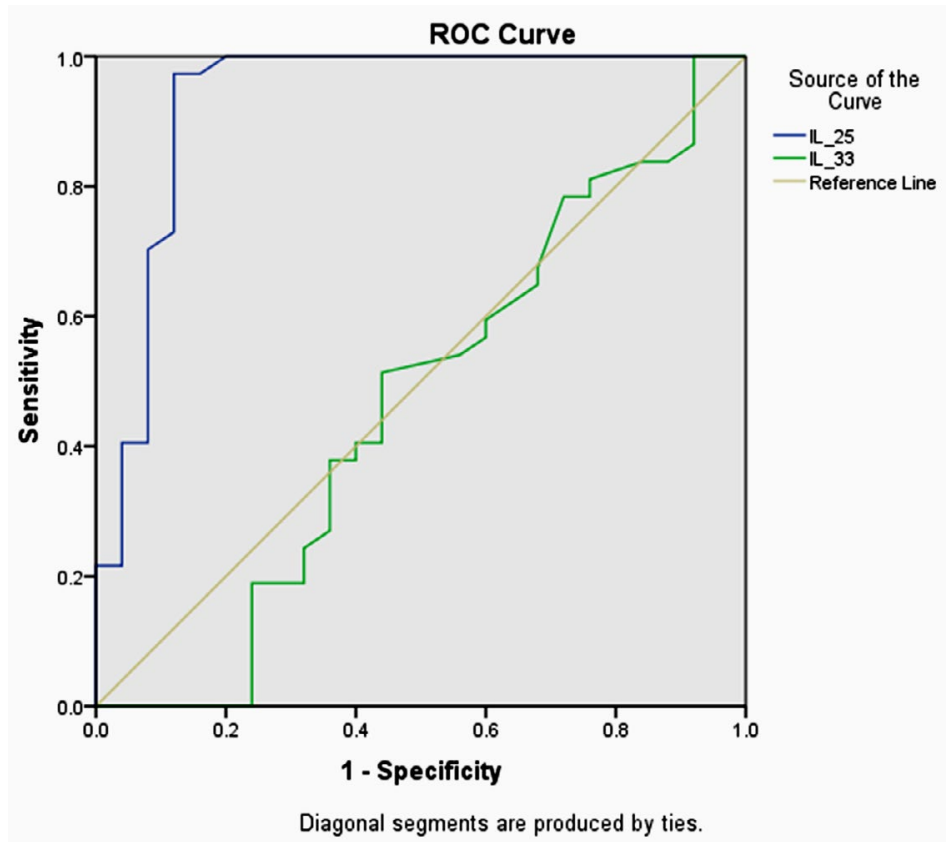

Fig. 1. ROC curves for optimal cutoff points at which IL-25 and IL-33 discriminate asthmatic patients from non asthmatic controls.

difference was reported in the level of IL33 according to type of treatment, highest readings of IL-33 was showed among patients with corticosteroids $(P<0.002)$. The variable of asthma family history also showed a notable statistical significance $(P<0.013)$ with regard to the concentration of IL-33.

ROC curve analysis of IL-25 and IL-33 showed cutoff values of $\geq 1.6350$ and $\geq 1.3100$, respectively.The sensitivity and specificity of IL-25 and IL-33 in association with PPVs and NPVs are listed in Table-2.

\section{DISCUSSION}

The present study revealed that IL- 25 was more sensitive than IL-33 in the diagnosis of asthma. One study showed increased IL25 expression in the mucosa of patients with bronchial asthma and in the skin of patients with eczema ${ }^{13}$.
Another study found that cigarette smoke was responsible for stimulating the airway epithelial cells for the production of thymic stromal lymphopoetin (TSLP) and, consequently, the dendritic cells that activate the polarization of $\mathrm{Th} 2^{14}$. The epithelial cells in the airway are the major exporters of IL-25, IL-33 and TSLP, which act upstream of the cytokines of Th2 that include interleukins 4, 5 and 13 and thus activate the immune response type of Th $2^{15}$. Therefore, cigarette smoke is considered to be a powerful and prime factor for airway inflammation, brought about by increased the TSLP production ${ }^{14}$. The inflammatory process and bronchoconstriction can be inhibited using montelukast ${ }^{16}$. Other studies also found that montelukast add-on therapy to the inhaled corticosteroids enabled effective control of persistent asthma ${ }^{17,18}$.

A study reported the association between elevated of IL-25 expression due to allergen 
exposure in patients with asthma and the disease severity ${ }^{8}$. According to the ROC analysis, this study revealed a low sensitivity and specificity of IL- 25 in the differentiation between patients with and without asthma. These results are inconsistent with that of the present study that revealed a high diagnostic sensitivity of IL-25 and also a non significant relationship between IL-25 serum level and severity of disease. Another study reported high sensitivity (93.5\%) and specificity $(60.0 \%)$ of IL- 25 in the diagnosis of airway hyperresponsiveness and this result is compatible with the results of our study ${ }^{19}$.

To conclude, this study highlights the need for more cellular and molecular investigations and extensive studies to recognize the role of interleukins 25 and 33 in pediatric asthma, which could improve the diagnostic and therapeutic strategies for this disease.

\section{CONCLUSION}

This study suggests that IL-25 shows higher diagnostic sensitivity and specificity than IL-33; therefore, IL-25 represents a significant marker for the diagnosis of pediatric asthma.

\section{ACKNOWLEDGMENTS}

I am thankful to the Department of Microbiology, College of Medicine, Kerbala University, Iraq for their collaboration in the achievement of the work.

\section{FUNDING}

None.

\section{DATA AVAILABILITY}

All datasets generated or analyzed during this study are included in the manuscript.

\section{ETHICS STATEMENT}

Not applicable.

\section{REFERENCES}

1. Mims JW. Asthma: definitions and pathophysiology. International Forum of Allergy \& Rhinology. 2015;5(S1):52-56.

2. Holloway JW, Yang IA, Holgate ST. Genetics of allergic disease. J Allergy Clin Immunol. 2010;125(2 Suppl 2):S81-S94. doi: 10.1016/j.jaci.2009.10.071

3. Harb $\mathrm{H}$, Renz $\mathrm{H}$. Update on epigenetics in allergic disease. J Allergy Clin Immunol. 2015;135: 15-24. doi: 10.1016/j.jaci.2014.11.009

4. Bunyavanich S, Schadt EE. Systems biology of asthma and allergic diseases: a multiscale approach. J Allergy Clin Immunol. 2015;135:31-42. doi: 10.1016/j. jaci.2014.10.015

5. Fahy JV. Type 2 inflammation in asthma present in most, absent in many. Nat Rev Immunol. 2015;15:5765. doi: $10.1038 / \mathrm{nri3786}$

6. Saenz SA, Siracusa MC, Perrigoue JG, et al. IL25 elicits a multipotent progenitor cell population that promotes $\mathrm{T}(\mathrm{H}) 2$ cytokine responses. Nature. 2010; 464: 13621366. doi: 10.1038/nature08901

7. Tang W, Smith SG, Salter B, et al. Allergen-Induced Increases in Interleukin-25 and Interleukin-25 Receptor Expression in Mature Eosinophils from Atopic Asthmatics. Int Arch Allergy Immunol. 2016; 170:234242. doi: $10.1159 / 000449248$

8. Paplinska-Goryca M, Grabczak EM, Dabrowska M, et al. Sputum interleukin-25 correlates with asthma severity: a preliminary study. Advances in Dermatology and Allergology. 2018;35(5):462-469. doi: 10.5114/ ada.2017.71428

9. Corrigan CJ, Wang W, Meng $Q$, et al. Allergeninduced expression of IL-25 and IL-25 receptor in atopic asthmatic airways and late-phase cutaneous responses. J Allergy Clin Immunol. 2011;128:116-124. doi: 10.1016/j.jaci.2011.03.043

10. Kian FC, Sally EW, Jan LB, et al. International ERS/ATS guidelines on definition, evaluation and treatment of severe asthma. European Respiratory Journal. 2014;43:343-373. doi: 10.1183/09031936.00202013

11. Castro-Rodriguez JA. A new childhood asthma phenotype: Obese with early menarche. Paediatric Respiratory Reviews. 2016;18:85-89. doi: 10.1016/j. prrv.2015.10.006

12. Dharmage SC, Perret JL, Custovic A. Epidemiology of Asthma in Children and Adults. Front Pediatr. 2019;7:246. doi: 10.3389/fped.2019.00246

13. Wang $\mathrm{YH}$, Angkasekwinai $\mathrm{P}$, Lu N, et al. IL-25 augments type 2 immune responses by enhancing the expansion and functions of TSLP-DC-activated Th2 memory cells. J Exp Med. 2007;204:1837-1847. doi: 10.1084/ jem. 20070406

14. Strzelak A, Ratajczak A, Adamiec A, Feleszko W. Tobacco Smoke Induces and Alters Immune Responses in the Lung Triggering Inflammation, Allergy, Asthma and Other Lung Diseases: A Mechanistic Review. Int J Environ Res Public Health. 2018;5:1033. doi: 10.3390/ ijerph15051033

15. Lloyd CM,Saglani S. Epithelial cytokines and pulmonary allergic inflammation. Curr Opin Immunol. 2015;34:5258. doi: 10.1016/j.coi.2015.02.001

16. Ikram A, Kumar V, Taimur M, Khan MA, Fareed S, Barry HD. Role of Montelukast in Improving Quality of Life in Patients with Persistent Asthma. Cureus. 2019;11(6):e5046. doi: 10.7759/cureus.5046

17. Virchow JC, Mehta A, Ljungblad L, Mitfessel H. Add-on montelukast in inadequately controlled asthma patients in a 6-month open-label study: the MONtelukast In Chronic Asthma (MONICA) study. Respir Med. 2010;104:644-651. doi: 10.1016/j. rmed.2009.11.022 
18. Bozek A, Warkocka-Szoltysek B, Filipowska-Gronska A,Jarzab J. Montelukast as an add-on therapy to inhaled corticosteroids in the treatment of severe asthma in elderly patients. J Asthma. 2012;49:530-534. doi: 10.3109/02770903.2012.680638

19. Chen F, Hong $\mathrm{H}$, Sun $\mathrm{Y}$, et al. Nasal interleukin 25 as a novel biomarker for patients with chronic rhinosinusitis with nasal polyps and airway hypersensitiveness: A pilot study. Ann Allergy Asthma Immunol. 2017;119(4):310316.e2. doi: 10.1016/j.anai.2017.07.012

20. Vanker A, Gie RP, Zar HJ. The association between environmental tobacco smoke exposure and childhood respiratory disease: a review. Expert Review of Rspiratory Mdicine. 2017;11(8): 661-673. doi: 10.1080/17476348.2017.1338949
21. Marseglia GL, Avanzini MA, Caimmi S, et al. Passive Exposure to Smoke Results in Defective Interferon- $\gamma$ Production by Adenoids in Children With Recurrent Respiratory Infections. Journal of Interferon and Cytokine Research. 2009;29(8):427-432. doi: 10.1089/ jir.2008.0108

22. Poddighe D, Brambilla I, Licari A, Marseglia GL. Omalizumab in the Therapy of Pediatric Asthma. Recent Patents on Inflammation \& Allergy Drug Discovery. 2018;12(2):103-109. doi: 10.2174/187221 3X12666180430161351

23. Earl CS, An S, Ryan RP. The changing face of asthma and its relation with microbes. Trends in Microbiology. 2015;23(7):408-418. doi: 10.1016/j.tim.2015.03.005 